\title{
Temporal order of cancers and mental disorders in an adult population
}

David Cawthorpe, Marc Kerba, Aru Narendran, Harleen Ghuttora, Gabrielle Chartier and Norman Sartorius

\section{Background}

Population-based examination of comorbidity is an emerging field of study.

\section{Aims}

The purpose of the present population level study is to expand our understanding of how cancer and mental illness are temporally associated.

\section{Method}

A sample of 83648056 physician billing records for 664838 (56\% female) unique individuals over the age of 18 was stratified on ages 19-49 years and 50+ years, with temporal order of mental disorder and cancer forming the basis of comparison.

\section{Results}

Mental disorders preceded cancers for both genders within each age strata. The full range of cancers and mental disorders preceding or following each pivot ICD class are described in terms of frequency of diagnosis and duration in days, with specific examples illustrated.

\section{Conclusions}

The temporal comorbidity between specific cancers and mental disorders may be useful in screening or clinical planning and may represent indicators of disease mechanism that warrant further screening or investigation.

\section{Declaration of interest}

None.

\section{Keywords}

Temporal comorbidity; cancer; mental disorder; physician diagnosis; population; adult; psychiatric disorder.

\section{Copyright and usage}

(c) The Royal College of Psychiatrists 2018. This is an Open Access article, distributed under the terms of the Creative Commons Attribution-NonCommercial-NoDerivatives licence (http://creativecommons.org/licenses/by-nc-nd/4.0/), which permits noncommercial re-use, distribution, and reproduction in any medium, provided the original work is unaltered and is properly cited. The written permission of Cambridge University Press must be obtained for commercial re-use or in order to create a derivative work.

\section{Importance of comorbidity}

Comorbidity refers to disorders and diseases that occur in tandem with likelihoods greater than expected by chance alone. ${ }^{1}$ The study of comorbidity has evolved rapidly in recent years since its formal description with respect to chronic disease by Feinstein et al. ${ }^{2}$ Yet the study of comorbidity remains complex and challenging, even as the field of comorbidity medicine continues to progress. ${ }^{1}$ Current definitions incorporate concepts such as multi-comorbidity in addition to simple two-diagnosis comorbidity, and the idea of etiological and non-etiological comorbidity, referring to its causal and independent forms, among others. ${ }^{1}$ Its applicability to clinical practice is limited and, although common, it remains poorly understood. ${ }^{1}$

With respect to cancer, study most frequently focuses on constrained sets of disorders related to a specific type of cancer. ${ }^{3-14}$ Other approaches often focus on proximal or prognostic comorbidity and employ comorbidity indices, such as the Charlson index. ${ }^{5,15-25}$

\section{Current evidence on the comorbidity of cancer and mental disorders}

Recent studies that examined the association between neoplasms, including cancer, and mental disorders focused on the association of mental morbidity in cancer patients and survivors, utilising diagnostic interviews and surveys to assess mental disorder status. ${ }^{26,27}$ Others have examined mental health problems and needs for social support post-diagnosis. ${ }^{28}$ While a population study approach is informative, especially when both mental and physical comorbidities are examined, studies are often cross-sectional ${ }^{27}$ and are biased by recall in interviews to assess mental status in association with cancer. ${ }^{29}$

\section{Population-based study}

One recent large population study, ${ }^{30}$ employing 10 years of data from Sweden's national registry of physician diagnoses, studied temporal data related to mental disorder, finding that mental disorder rates increased 10 months before cancer, peaking immediately after and remaining elevated for the study duration. Findings were strongest with cancers that had a poorer prognosis. The overall long-term co-occurrence in a population of any mental disorder and any cancer has not been reported in the reviewed literature.

While the temporal order of disorder and disease arising in any given patient is identified in terms of the progress of time, the population-based study of the temporal order of comorbid diseases may be bidirectional in time, given the advent of large data-sets, as the 10-year Swedish study ${ }^{30}$ and others ${ }^{31}$ have demonstrated. Such studies have formed the groundwork for better understanding the temporal relationship between cancers and mental disorders.

\section{Potential mechanisms}

There is a growing body of evidence showing that systemic inflammation mediated by pro-inflammatory cytokines can facilitate tumour growth and metastasis. ${ }^{32-35}$ Inflammation-based prognostic scores have been found to be independently associated with survival in cancer, independent of tumour type. Furthermore, antipsychotic medications, in addition to stress and mental disorder, affect central nervous system cell-cell communication, it is possible that they also modulate immunity and inflammation.

Other research has shown that environmental factors can lead to epigenetic changes. Bioactive nutrients and gut microbiota can alter DNA methylation and modulate the 'gut-brain axis' via their influence on inflammatory cytokines and production of antimicrobial peptides. ${ }^{36}$ It is biologically plausible that similar pathways or conditions drive the development of both cancer and mental illness; ${ }^{37}$ however, the temporal association of such factors remains confounded by treatment and is largely unstudied. 


\section{Purpose of present study}

The purpose of the current study was to expand our present understanding of comorbidity. Using a 16-year, regional population dataset, we examined, separately for males and females, the relationship between all neoplasms (cancers) before and after any mental disorder and all mental disorders before and after any neoplasm, where these physician-diagnosed main ICD classes co-occurred. We hypothesised that specific mental disorders and neoplasms would arise significantly in proportion before or after the pivot ICD classes of interest (neoplasm or mental disorder).

\section{Method}

To be paid for services, physicians must submit forms for each encounter to the Provincial government that include diagnosis (up to three per claim). All regional provincial physician billing records data from the Calgary Health Zone, Alberta, Canada, representing physician-diagnosed ICD-9 classification, age, gender and diagnosis date between Spring 1993 and Fall 2010 were analysed. The sample consisted of 75944698 records for 525439 (55\% female) unique individuals over the age of 18 . The data represent the majority of the residing population over the period, including those that moved to and away from the region, or were deceased. Additional regional systems (emergency, in-patient, ambulatory) that also record physician diagnosis were not considered to avoid redundancy.

Data were grouped based on Boolean association within the two main ICD classes, with neoplasm and mental disorder independently linked to all associated ICD disorders. For the purpose of comparison between and within groups, odds ratios (OR). In addition to ORs, data were also grouped so that the first date of diagnosis of any disorder for each patient could be compared with the first date of diagnosis by class (any mental disorder or any neoplasm) and by specific main ICD diagnosis within the class (any mental disorder or neoplasm). It was rare for mental disorder and cancer to be diagnosed on the same visit day, and such cases were not included in the analysis (242 males/31 439 diagnoses and 267 females/45 826 diagnoses for all disorders). Age represents a potential confounder. Age (mean and standard deviation) was reported in addition to ORs for each group overall and within age stratification (19-49 years and $50+$ years). Additional comorbidities (e.g., obesity and diabetes) while potentially influential, were not considered.

In addition, the duration between the first date of diagnosis for mental disorders associated with neoplasms and cancers was calculated. The total frequency of specific diagnoses arising for each diagnosis within the duration interval before and after the pivot diagnosis (any mental disorder or neoplasm) was also calculated for comparison. The proportions of the diagnostic frequencies for each specific diagnosis were calculated for comparison.

Statistical differences were estimated based on comparison of the 95\% confidence intervals (CI). Non-overlapping 95\% CIs with $z$ set to 1.96 indicated a statistical difference $(P<0.05)$.

There are multiple ways to count different groups for the purpose of meaningful comparison: (a) number of unique individuals within defined groups or ICD classes, or individual diagnoses; (b) cumulative frequency of diagnoses for individuals within defined groups or ICD classes, or individual diagnoses; and (c) the temporal order of counts and frequencies comparing counts within defined groups or ICD classes, or individual diagnoses within diagnostic groups of main ICD diagnostic categories $(n=1036)$. In this analysis, there were two temporal groupings for each gender based on two pivot classes of ICD diagnoses (neoplasm and mental disorder), wherein counts of unique individuals, frequencies and average durations arising before and after each pivot diagnosis (before and after any neoplasm; before and after any mental disorder) were calculated overall for age and gender, and for each independent diagnosis by age and gender temporal grouping. Further, the base rate of mental disorder in the present sample was $54 \%$ over 16 years. $^{31}$

After a general description of the sample and the overall relationships within and between groups, we examined the specific neoplasms arising before or after any mental disorder, and the specific mental disorders arising before or after any neoplasm. Specific examples are detailed (e.g., specific diagnoses within the pivot diagnosis account for the observed significance). The data were analysed using Stata 14. Each table result was verified using two independent algorithms: 'contract' $v$. 'unique' to verify counts of unique individuals within groupings, and 'collapse' for calculating cumulative frequency and duration within diagnoses by temporal grouping.

\section{Results}

Table 1 provides the unique individual counts and the associated cumulative frequencies of diagnoses within each condition. Note the increased counts under the condition of mental disorder before cancer for both genders. The proportion of those with any mental disorder before cancer was higher for males and females in both age groups. For example, for $58 \%$ of males and $63 \%$ of

\begin{tabular}{|c|c|c|c|c|c|c|}
\hline \multirow[t]{2}{*}{ Gender } & \multirow[t]{2}{*}{ Condition } & \multirow[t]{2}{*}{ Age in years, mean (s.d.) } & \multicolumn{2}{|c|}{ 19-49 years } & \multicolumn{2}{|c|}{$50+$ years } \\
\hline & & & Unique individuals & Records & Unique individuals & Records \\
\hline \multirow[t]{7}{*}{ Female } & All & $45.2(17.6)$ & 218951 & 18230305 & 77497 & 31672669 \\
\hline & No CA No MD & $32.6(23.9)$ & 48607 & 962890 & 11557 & 2272041 \\
\hline & No CA MD & $41.6(22.8)$ & 76112 & 4835023 & 22258 & 10658944 \\
\hline & CA No MD & $46.3(22.5)$ & 17250 & 1251853 & 7787 & 1800661 \\
\hline & CA MD & $60(20.4)$ & 76982 & 11180539 & 35895 & 16941023 \\
\hline & $\mathrm{MD}>\mathrm{CA}$ & $54.7(20.3)$ & 23919 & 3946837 & 13416 & 4568128 \\
\hline & $\mathrm{MD}<\mathrm{CA}$ & $51.5(18.8)$ & 52913 & 7213045 & 22390 & 12350571 \\
\hline \multirow[t]{7}{*}{ Males } & All & $46.7(16.6)$ & 176403 & 10631071 & 52588 & 15410653 \\
\hline & No CA No MD & $29.5(23.1)$ & 66260 & 669381 & 9715 & 2248147 \\
\hline & No CA MD & $38.5(22.7)$ & 62838 & 2399684 & 12830 & 6537408 \\
\hline & CA No MD & $47.1(23.8)$ & 14706 & 1028681 & 6929 & 1129633 \\
\hline & CA MD & $55.6(22.2)$ & 32599 & 6533325 & 23114 & 5495465 \\
\hline & $\mathrm{MD}>\mathrm{CA}$ & $61.2(19.5)$ & 11112 & 2637453 & 9626 & 1551329 \\
\hline & $\mathrm{MD}<\mathrm{CA}$ & 56.7 (18) & 21366 & 3880494 & 13396 & 3930110 \\
\hline
\end{tabular}


Table 2 Odds ratios by condition by gender by age strata

\begin{tabular}{llcc|} 
Gender & Condition & 19-49 years $(95 \% \mathrm{Cl})$ & 50+ years $(95 \% \mathrm{Cl})$ \\
\hline Female & Overall & $2.85(2.79,2.91)$ & $2.39(2.32,2.47)$ \\
& $\mathrm{MD}>\mathrm{CA}$ & $0.89(0.87,0.91)$ & $0.9(0.86,0.93)$ \\
& $\mathrm{MD}<\mathrm{CA}$ & $1.96(1.92,2)$ & $1.49(1.44,1.55)$ \\
\hline \multirow{2}{*}{ Male } & Overall & $2.34(2.29,2.39)$ & $2.53(2.43,2.62)$ \\
& $\mathrm{MD}>\mathrm{CA}$ & $0.8(0.78,0.82)$ & $1.05(1.01,1.1)$ \\
& $\mathrm{MD}<\mathrm{CA}$ & $1.53(1.5,1.57)$ & $1.46(1.41,1.52)$ \\
CA, cancer; $\mathrm{MD}$, mental disorder; $>$, after; $<$, before. & \\
\hline
\end{tabular}

females aged 19-49 years, any mental disorder preceded any cancer. For $69 \%$ of males and $66 \%$ of females over 50 years of age, any mental disorder preceded any cancer.

Table 2 shows the overall ORs for each category by gender for the two age strata. Males and females were more likely to have both mental disorder and cancer compared to either one or neither, and for both genders, it was more likely that any neoplasm would follow any mental disorder. This was the case for each age category. When stratified by age, the ORs for the 19-49-year-old group are consistent within the age strata and slightly greater than those for the group over 50 years of age, even though the proportions of those with both mental disorder and neoplasm are greater in the over 50 years of age strata for both genders (Table 1).

Table 3 provides a comparison of average age, cumulative diagnostic frequency, average duration, and frequency proportions by pivot diagnosis by independent diagnoses. Examples of serious diagnoses for each pivot category for males and females include schizophrenic disorders (295), affective psychoses (296) and other nonorganic psychoses (298), representing ICD diagnoses that arise with considerable frequency - potentially reflecting intensity - within these patients. Note that this table represents the summed counts or frequency of diagnoses within each ICD main diagnosis under the condition of arising before and after each ICD pivot. ICD disorder 306 (psychological distress) was the only disorder arising significantly after neoplasm in both females and males. Only in males was there one non-significant disorder, ICD disorder 313 (emotional distress). Table 3 identifies the specific neoplasm and mental disorders underpinning the overall ORs shown in Table 2.

As shown in Table 3, for females, when any cancer was the pivot diagnosis, the average age was 51 years, the average time cancer arose before the specified mental disorders was 2191 days, and the average time after the specified mental disorders was 1378 days. For females, when any mental disorder was the pivot diagnosis, the average age was 59 years, the average time cancer arose before the specified mental disorders was 2311 days, and the average time after the specified mental disorders was 885 days. The specific mental disorder in females with the shortest duration (1423 days) before cancer was psycho-physiological gastro-intestinal disorder (306), and that with the longest duration (2894 days) was intellectual disability not otherwise specified (319). The specific cancer in females with the shortest duration (302 days) arising after any mental disorder was malignant neoplasm - pancreas (157), and that with the longest duration (1549 days) arising after any mental disorder was malignant neoplasm - major salivary (142).

As shown in Table 3, for males, when any cancer was the pivot diagnosis, the average age was 50 years, the average time cancer arose before the specified mental disorders was 2045 days, and the average time after the specified mental disorders was 1420 days. For males, when any mental disorder was the pivot diagnosis, the average age was 61 years, the average time cancer arose before the specified mental disorders was 2114 days, and the average time after the specified mental disorders was 868 days. The specific mental disorder in males with the shortest duration before cancer was senile/presenile psychosis (290), and that with the longest duration was other mental retardation (318). The specific cancer in males with the shortest duration arising after any mental disorder was malignant neoplasm of lip, oral cavity, and pharynx (140), and that with the longest duration arising after any mental disorder was haemangioma/lymphangioma (228).

Table 3 also shows a wide range of frequencies or counts of each diagnosis before or after the pivot diagnosis, as well as the frequency proportions of the total for each specific diagnosis that arose before and after each pivot diagnosis.

\section{Summary of results}

The results shown in the tables illustrate in detail the overall and temporal relationships between ICD mental disorders and cancers as categories of diagnosis. Table 3 provides more depth of temporal information about the specific temporal relationships of the ICD diagnoses associated with each pivot diagnosis (any cancer or mental disorder), where both mental disorder and cancer arose in the same person at different times. Mental disorders preceded cancers, independent of age, for both genders. Table 3 provides a basis for examining the relative intensity and the average durations before and after each pivot diagnosis to provide an index of sequence or order.

\section{Discussion}

Our findings support the study of comorbid disorders, advancing the field by comprehensively examining the relationship between neoplasms, including cancer, and mental disorder, information that until now was not available. The results represent an important advance detailing the 16-year relationship between all cancers and all mental disorders in a large population, supporting future laboratory research on plausible biological mechanisms potentially linking a variety of disorders - for example, the effect of antipsychotics on cadherin-mediated cell-cell adhesion. ${ }^{38}$

The results of the present study are most comparable to those of a Swedish national study of mental disorder and cancer. ${ }^{30,39}$ Yet, the results of the present study are materially different. The Swedish study examined the relationship between cancer and mental disorder, noting an increase in relative risk from 2 years before the onset of cancer and finding that cancer predisposed people to psychological distress and mental disorder from 2 years before to after the onset of cancer for the study duration. ${ }^{30}$ Our results are the opposite of the Swedish study results, showing that, if random, cancer and mental disorders had equal odds of arising either before or after one another, according to the null hypothesis. We observed a strong relationship between mental disorder and cancer, with mental disorder preceding cancer. The differences in findings may be due to the 16-year time-based approach, or the different analytical methods employed, or both.

The strength of the temporal relationship between mental disorder and cancer illustrated in this paper is similar to that shown by another study based on this data sample. In that study, the temporal relationship between mental disorder and ulcerative colitis ${ }^{31}$ pointed to a potential mechanism for the onset of anxiety and depression preceding the onset of ulcerative colitis. This effect might be related to one or more of the principal medications used to treat these disorders, such as selective serotonin reuptake inhibitors. For example, there was no relationship with thought disorders or psychosis, for which a different class of medications is used in treatment. Psychotropic drugs probably do not only modulate cell 
Table 3 Comparison of ICD diagnoses (frequency and average duration) by group arising before and after pivot diagnoses

\begin{tabular}{|c|c|c|c|c|c|c|c|c|}
\hline Gender & Pivot diagnostic category & $\begin{array}{l}\text { Age, } \\
\text { years }\end{array}$ & $\begin{array}{c}\text { Duration of } \\
\text { diagnosis } \\
\text { before pivot, } \\
\text { days }\end{array}$ & Frequency & $\begin{array}{c}\text { Duration of } \\
\text { diagnosis } \\
\text { after pivot, } \\
\text { days }\end{array}$ & Frequency & $\begin{array}{l}\text { Proportion } \\
\text { before pivot }\end{array}$ & $\begin{array}{l}\text { Proportion } \\
\text { after pivot }\end{array}$ \\
\hline \multicolumn{9}{|c|}{ Psychosis (290-299) } \\
\hline $\mathrm{F}$ & Senile/presenile psychoses (290) & 83 & 2574 & 148264 & 742 & 19662 & 0.88 & 0.12 \\
\hline $\mathrm{F}$ & Alcoholic psychoses (291) & 64 & 2647 & 2668 & 1250 & 644 & 0.81 & 0.19 \\
\hline $\mathrm{F}$ & Drug psychoses (292) & 47 & 2215 & 2798 & 1347 & 1230 & 0.69 & 0.31 \\
\hline $\mathrm{F}$ & Transient organic mental disorder (293) & 66 & 2492 & 13566 & 1089 & 2713 & 0.83 & 0.17 \\
\hline $\mathrm{F}$ & Other organic psychotic condition (294) & 70 & 2241 & 10357 & 1009 & 2191 & 0.83 & 0.17 \\
\hline $\mathrm{F}$ & Schizophrenic disorders (295) & 50 & 2139 & 113094 & 1418 & 54195 & 0.68 & 0.32 \\
\hline $\mathrm{F}$ & Affective psychoses (296) & 50 & 2183 & 181036 & 1423 & 80407 & 0.69 & 0.31 \\
\hline $\mathrm{F}$ & Paranoid states (297) & 64 & 2139 & 6500 & 1421 & 3350 & 0.66 & 0.34 \\
\hline $\mathrm{F}$ & Other nonorganic psychoses (298) & 52 & 2463 & 32465 & 1103 & 8261 & 0.8 & 0.2 \\
\hline $\mathrm{F}$ & Psychoses of childhood (299) & 49 & 1972 & 167 & 1525 & 120 & 0.58 & 0.42 \\
\hline \multicolumn{9}{|c|}{ Neurotic disorders, personality disorders, and other nonpsychotic mental disorders (300-316) } \\
\hline $\mathrm{F}$ & Neurotic disorders (300) & 51 & 2012 & 487223 & 1516 & 271633 & 0.64 & 0.36 \\
\hline $\mathrm{F}$ & Personality disorders (301) & 41 & 2088 & 36525 & 1442 & 17293 & 0.68 & 0.32 \\
\hline $\mathrm{F}$ & Sexual disorders (302) & 42 & 1732 & 1290 & 1566 & 726 & 0.64 & 0.36 \\
\hline $\mathrm{F}$ & Alcohol dependence syndrome(303) & 49 & 2253 & 19060 & 1422 & 8774 & 0.68 & 0.32 \\
\hline $\mathrm{F}$ & Drug dependence (304) & 43 & 2458 & 27353 & 1295 & 10324 & 0.73 & 0.27 \\
\hline $\mathrm{F}$ & Nondependent drug abuse (305) & 46 & 2099 & 13338 & 1488 & 7377 & 0.64 & 0.36 \\
\hline $\mathrm{F}$ & Psycho-physiological gastro-intestinal disorder (306) & 52 & 1423 & 6141 & 1560 & 7727 & 0.44 & 0.56 \\
\hline $\mathrm{F}$ & Special symptom (307) & 42 & 2090 & 46693 & 1470 & 24077 & 0.66 & 0.34 \\
\hline $\mathrm{F}$ & Acute reaction to stress (308) & 50 & 1929 & 79187 & 1527 & 48065 & 0.62 & 0.38 \\
\hline $\mathrm{F}$ & Adjustment reaction (309) & 48 & 2083 & 123687 & 1518 & 61042 & 0.67 & 0.33 \\
\hline $\mathrm{F}$ & Nonpsychotic brain syndrome(310) & 61 & 2354 & 7279 & 1262 & 1806 & 0.8 & 0.2 \\
\hline $\mathrm{F}$ & Depressive disorder (311) & 50 & 2084 & 573543 & 1487 & 290981 & 0.66 & 0.34 \\
\hline $\mathrm{F}$ & Conduct disturbance (312) & 55 & 2306 & 4198 & 1297 & 1670 & 0.72 & 0.28 \\
\hline $\mathrm{F}$ & Emotional disorder childhood/adolescence (313) & 43 & 1721 & 2944 & 1738 & 2749 & 0.52 & 0.48 \\
\hline $\mathrm{F}$ & Hyperkinetic syndrome (314) & 40 & 2181 & 5781 & 1330 & 1873 & 0.76 & 0.24 \\
\hline $\mathrm{F}$ & Specific developmental delays (315) & 42 & 2167 & 1042 & 1305 & 317 & 0.77 & 0.23 \\
\hline $\mathrm{F}$ & Psychic factors associated with other disorder (316) & 52 & 1808 & 10545 & 1451 & 5423 & 0.66 & 0.34 \\
\hline \multicolumn{9}{|c|}{ Mental retardation (317-319) } \\
\hline $\mathrm{F}$ & Mild intellectual disability (317) & 47 & 2822 & 1154 & 1469 & 691 & 0.63 & 0.37 \\
\hline $\mathrm{F}$ & Other mental retardation (318) & 46 & 2149 & 306 & 1415 & 227 & 0.57 & 0.43 \\
\hline $\mathrm{F}$ & Intellectual disability not otherwise specified (NOS) (319) & 41 & 2894 & 243 & 1442 & 135 & 0.64 & 0.36 \\
\hline Gender & Any MD is pivot & Age, years & $\begin{array}{r}\text { MD before } \\
\text { CA, days }\end{array}$ & $\begin{array}{l}\text { MD before CA } \\
\text { Frequency }\end{array}$ & $\begin{array}{l}\text { MD after } \\
\text { CA, days }\end{array}$ & $\begin{array}{l}\text { MD after CA } \\
\text { Frequency }\end{array}$ & $\begin{array}{l}\text { Proportion } \\
\text { MD before }\end{array}$ & $\begin{array}{r}\text { Proportion } \\
\text { MD after }\end{array}$ \\
\hline \multicolumn{9}{|c|}{ Malignant (mal) neoplasm (neo) of lip, oral cavity, and pharynx (140-149) } \\
\hline $\mathrm{F}$ & Mal neo lip (140) & 69 & 2260 & 3445 & 699 & 308 & 0.92 & 0.08 \\
\hline $\mathrm{F}$ & Mal neo tongue (141) & 65 & 2563 & 1020 & 641 & 96 & 0.91 & 0.09 \\
\hline $\mathrm{F}$ & Mal neo major salivary (142) & 57 & 2496 & 503 & 1549 & 128 & 0.8 & 0.2 \\
\hline $\mathrm{F}$ & Mal neo gum (143) & 67 & 3141 & 206 & 419 & 19 & 0.92 & 0.08 \\
\hline $\mathrm{F}$ & Mal neo mouth floor (144) & 60 & 2643 & 236 & 778 & 49 & 0.83 & 0.17 \\
\hline $\mathrm{F}$ & Mal neo of other and unspecified parts of mouth (145) & 64 & 2645 & 959 & 676 & 179 & 0.84 & 0.16 \\
\hline $\mathrm{F}$ & Mal neo oropharynx (146) & 61 & 2713 & 556 & 540 & 101 & 0.85 & $\begin{array}{c}0.15 \\
\text { (Continued) }\end{array}$ \\
\hline
\end{tabular}




\begin{tabular}{|c|c|c|c|c|c|c|c|c|}
\hline Gender & Any MD is pivot & Age, years & $\begin{array}{l}\text { MD before } \\
C A \text {, days }\end{array}$ & $\begin{array}{l}\text { MD before CA } \\
\text { Frequency }\end{array}$ & $\begin{array}{l}\text { MD after } \\
\text { CA, days }\end{array}$ & $\begin{array}{l}\text { MD after CA } \\
\text { Frequency }\end{array}$ & $\begin{array}{l}\text { Proportion } \\
\text { MD before }\end{array}$ & $\begin{array}{r}\text { Proportion } \\
\text { MD after }\end{array}$ \\
\hline $\mathrm{F}$ & Mal neo nasopharynx (147) & 61 & 1744 & 554 & 1308 & 37 & 0.94 & 0.06 \\
\hline $\mathrm{F}$ & Mal neo hypopharynx (148) & 66 & 2379 & 144 & 731 & 17 & 0.89 & 0.11 \\
\hline $\mathrm{F}$ & Other mal neo oropharynx (149) & 71 & 2515 & 339 & 678 & 34 & 0.91 & 0.09 \\
\hline \multicolumn{9}{|c|}{ Malignant neoplasm of digestive organs and peritoneum (150-159) } \\
\hline $\mathrm{F}$ & Mal neo oesophagus (150) & 69 & 2409 & 2698 & 525 & 200 & 0.93 & 0.07 \\
\hline $\mathrm{F}$ & Mal neo stomach (151) & 69 & 2113 & 3484 & 576 & 392 & 0.9 & 0.1 \\
\hline $\mathrm{F}$ & Mal neo small bowel (152) & 63 & 2286 & 738 & 210 & 79 & 0.9 & 0.1 \\
\hline $\mathrm{F}$ & Mal neo colon (153) & 70 & 2371 & 19389 & 728 & 2701 & 0.88 & 0.12 \\
\hline $\mathrm{F}$ & Mal neo rectum/anus (154) & 66 & 2278 & 7292 & 902 & 1219 & 0.86 & 0.14 \\
\hline $\mathrm{F}$ & Mal neo liver (155) & 63 & 2443 & 4440 & 566 & 343 & 0.93 & 0.07 \\
\hline $\mathrm{F}$ & Mal neo gallbladder and extrahepatic bile ducts (156) & 69 & 2240 & 1500 & 402 & 117 & 0.93 & 0.07 \\
\hline $\mathrm{F}$ & Mal neo pancreas (157) & 71 & 2531 & 7918 & 308 & 409 & 0.95 & 0.05 \\
\hline $\mathrm{F}$ & Mal neo peritoneum (158) & 62 & 2027 & 672 & 515 & 43 & 0.94 & 0.06 \\
\hline $\mathrm{F}$ & Other mal neo gastro-intestine /peritoneum (159) & 66 & 1950 & 438 & 564 & 47 & 0.9 & 0.1 \\
\hline \multicolumn{9}{|c|}{ Malignant neoplasm of respiratory and intrathoracic organs (160-165) } \\
\hline $\mathrm{F}$ & Mal neo of nasal cavities, middle ear, and accessory sinuses (160) & 56 & 2849 & 770 & 564 & 113 & 0.87 & 0.13 \\
\hline $\mathrm{F}$ & Mal neo larynx (161) & 69 & 2073 & 1300 & 800 & 199 & 0.87 & 0.13 \\
\hline $\mathrm{F}$ & Mal neo trachea/lung (162) & 70 & 2492 & 35892 & 431 & 2288 & 0.94 & 0.06 \\
\hline $\mathrm{F}$ & Mal neo pleura (163) & 61 & 2840 & 468 & 590 & 55 & 0.89 & 0.11 \\
\hline $\mathrm{F}$ & Mal neo of thymus, heart, and mediastinum (164) & 55 & 2378 & 834 & 488 & 92 & 0.9 & 0.1 \\
\hline $\mathrm{F}$ & $\begin{array}{l}\text { Mal neo of other and ill-defined sites within the respiratory } \\
\text { system and intrathoracic organs (165) }\end{array}$ & 50 & 2445 & 1039 & 1241 & 233 & 0.82 & 0.18 \\
\hline \multicolumn{9}{|c|}{ Malignant neoplasm of bone, connective tissue, skin, and breast (170-175) } \\
\hline $\mathrm{F}$ & Mal neo bone/artic cart (170) & 59 & 2487 & 1136 & 925 & 210 & 0.84 & 0.16 \\
\hline $\mathrm{F}$ & Mal neo soft tissue (171) & 54 & 2424 & 3297 & 937 & 496 & 0.87 & 0.13 \\
\hline $\mathrm{F}$ & Mal melanoma skin (172) & 57 & 2454 & 7813 & 1107 & 1775 & 0.81 & 0.19 \\
\hline $\mathrm{F}$ & Other mal neo skin (173) & 68 & 2500 & 53882 & 1234 & 12822 & 0.81 & 0.19 \\
\hline $\mathrm{F}$ & Mal neo female breast (174) & 59 & 2435 & 82325 & 891 & 9825 & 0.89 & 0.11 \\
\hline \multicolumn{9}{|c|}{ Mal neoplasm of genitourinary organs (179-189) } \\
\hline $\mathrm{F}$ & Mal neo uterus NOS (179) & 69 & 2365 & 1109 & 994 & 133 & 0.89 & 0.11 \\
\hline $\mathrm{F}$ & Mal neo cervix uteri (180) & 50 & 1940 & 4750 & 734 & 810 & 0.85 & 0.15 \\
\hline $\mathrm{F}$ & Mal neo placenta (181) & 54 & 1722 & 78 & 824 & 16 & 0.83 & 0.17 \\
\hline $\mathrm{F}$ & Mal neo uterus body (182) & 67 & 2414 & 3207 & 801 & 590 & 0.84 & 0.16 \\
\hline $\mathrm{F}$ & Mal neo uterine adnexa (183) & 61 & 2489 & 16757 & 668 & 1736 & 0.91 & 0.09 \\
\hline $\mathrm{F}$ & Mal neo of other and unspecified female genital organs (184) & 61 & 2075 & 1840 & 705 & 262 & 0.88 & 0.12 \\
\hline $\mathrm{F}$ & Mal neo bladder (188) & 71 & 2339 & 10142 & 1084 & 1913 & 0.84 & 0.16 \\
\hline $\mathrm{F}$ & Mal neo of kidney and other and unspecified urinary organs (189) & 67 & 2472 & 5275 & 867 & 665 & 0.89 & 0.11 \\
\hline \multicolumn{9}{|c|}{ Malignant neoplasm of other and unspecified sites (190-199) } \\
\hline $\mathrm{F}$ & Mal neo eye (190) & 59 & 2236 & 844 & 1083 & 131 & 0.87 & 0.13 \\
\hline $\mathrm{F}$ & Mal neo brain (191) & 58 & 2296 & 6344 & 535 & 534 & 0.92 & 0.08 \\
\hline $\mathrm{F}$ & Mal neo of other and unspecified parts of nervous system (192) & 59 & 2171 & 516 & 997 & 77 & 0.87 & 0.13 \\
\hline $\mathrm{F}$ & Mal neo thyroid (193) & 51 & 2161 & 4202 & 1077 & 872 & 0.83 & 0.17 \\
\hline $\mathrm{F}$ & Mal neo other endocrine (194) & 58 & 1614 & 1202 & 1099 & 90 & 0.93 & 0.07 \\
\hline $\mathrm{F}$ & Mal neo other/ill-defined site (195) & 64 & 1940 & 728 & 448 & 120 & 0.86 & 0.14 \\
\hline $\mathrm{F}$ & Mal neo lymph nodes (196) & 63 & 2807 & 1444 & 757 & 240 & 0.86 & 0.14 \\
\hline $\mathrm{F}$ & Secondary mal neo of respiratory and digestive systems (197) & 66 & 2568 & 2874 & 372 & 241 & 0.92 & 0.08 \\
\hline $\mathrm{F}$ & Sec mal neo other sites (198) & 61 & 2661 & 1640 & 470 & 118 & 0.93 & $\begin{array}{c}0.07 \\
\text { (Continued) }\end{array}$ \\
\hline
\end{tabular}


MD before

Gender $\quad$ Any MD is pivot

Mal neo NOS (199)

Age, years

lasm of Iymphatic and hematopoietic tissue (200-208)

Malignant neoplasm of lymosarcoma and reticulosarcoma (200)

Hodgkin's disease (201)

Other mal neo lymph/histio (202)

Multiple myeloma and immunoproliferative neoplasms (203)

Lymphoid leukaemia (204)

Myeloid leukaemia (205)

Monocytic leukaemia (206)

Other specified leukaemia (207)

Leukaemia-unspecified cell (208)

Benign (ben) neoplasms (210-229)

Ben neo of lip, oral cavity, and pharynx (210)

Other ben neo gastro-intestine (211)

Ben neo of respiratory and intrathoracic organs (212)

Ben neo of bone and articular cartilage (213)

Lipoma (214)

Other ben neo soft tissue (215)

Ben neo of skin (216)

Ben neo breast (217)

Uterine leiomyoma (218)

Other ben neo uterus (219)

Ben neo ovary (220)

Ben neo other fem genital (221)

Ben neo urinary (223)

Ben neo of eye (224)

Ben neo nervous system (225)

Ben neo thyroid (226)

Ben neo other endocrine (227)

Haemangioma and lymphangioma, any site (228)

Ben neo of other and unspecified sites (229)

Carcinoma in situ (230-234)

Carcinoma in situ digestive org (230)

Carcinoma in situ respiratory (231)

Carcinoma in situ skin (232)

Carcinoma in situ of breast and genitourinany system (233)

Carcinoma in situ of other and unspecified sites (234)

Neoplasms of uncertain behaviour (235-238)

F

$$
\begin{aligned}
& \text { (235) } \\
& \text { Neo of uncer }
\end{aligned}
$$

F N Neo of uncertain behaviour of genitourinary organs (236) of uncertain behaviour of endocrine glands and nervous system (237)

67
62
51
64
68
66
57
56
60
65

53
60
60
47
50
49
49
50
46
46
45
46
57
59
56
49
48
44
47
47
67
70
70
47
63
4

$67 \quad 2225$

2048

2101
2345

2345
2352

2193

2019

2267
2530

2614

2121

2097

2329

2234

2233
2296

2296
2132

2132
2198

2427

2389

2326

2712

2700

1912
2371

2371
1772

1772
2168

2074

2167

2337

2880

2259

2163

2185

2175

52
49
MD before CA

MD after

MD a

MD after CA

Proportion

CA, days

Frequency

Proportion

MD befor

Proportion

$8094 \quad 522$

$$
681
$$

0.92

0.08

7115

2397
6072

763
609

609
715
561

5597

5114

3238
254

503

1105

1576

514
715

715
772

972

435

55

910

851
680

94

0.82
0.82

0.82
0.89

0.89
0.88
0.84
0.88

0.84
0.88
0.82

0.82
0.9

0.9
0.92

0.18

3095
23689
1796

1796
1032
10405

1213
1137

1137

7822
149562

149562
22412

22412
12972

12972
977

4282

813

469

935
2995
1093

1093

840
4511

1351

1784

978

6940
1242

1327

1143

934
3952

468

286

3143

1201
1214

1214
1204

1204
1198

1198
1186

1103

1190

1013

1135

875
1170

1019

1205
1289

0.77

0.86
0.79

0.79
0.78

0.78
0.77

0.77
0.78

42320

7404

4017
249

249
929

228

56

686

320
255

255
1335

439

760

532

1167

1050

611

865

946

883 


\begin{tabular}{|c|c|c|c|c|c|c|c|c|}
\hline Table 3 & Any MD is pivot & Age, years & $\begin{array}{r}\text { MD before } \\
\text { CA, days }\end{array}$ & $\begin{array}{l}\text { MD before } \mathrm{CA} \\
\text { Frequency }\end{array}$ & $\begin{array}{l}\text { MD after } \\
\text { CA, days }\end{array}$ & $\begin{array}{l}\text { MD after CA } \\
\text { Frequency }\end{array}$ & $\begin{array}{l}\text { Proportion } \\
\text { MD before }\end{array}$ & $\begin{array}{r}\text { Proportion } \\
\text { MD after }\end{array}$ \\
\hline $\mathrm{F}$ & $\begin{array}{l}\text { Neo of uncertain behaviour of other and } \\
\text { unspecified sites and tissues (238) }\end{array}$ & 55 & 2493 & 25248 & 1170 & 5112 & 0.83 & 0.17 \\
\hline $\mathrm{F}$ & Unspecified neo (239) & 54 & 2033 & 5725 & 1084 & 1623 & 0.78 & 0.22 \\
\hline Gender & Any CA is Pivot & Age, years & $\begin{array}{l}\text { CA before } \\
\text { MD, days }\end{array}$ & $\begin{array}{l}\text { CA before MD } \\
\text { Frequency }\end{array}$ & $\begin{array}{l}\text { CA after MD, } \\
\text { days }\end{array}$ & $\begin{array}{l}\text { CA after MD } \\
\text { Frequency }\end{array}$ & $\begin{array}{l}\text { Proportion } \\
\text { CA before }\end{array}$ & $\begin{array}{l}\text { Proportion } \\
\text { CA after }\end{array}$ \\
\hline \multicolumn{9}{|c|}{ Psychosis (290-299) } \\
\hline M & Senile/presenile psychoses (290) & 80 & 2564 & 84580 & 714 & 10751 & 0.89 & 0.11 \\
\hline M & Alcoholic psychoses (291) & 57 & 2087 & 4940 & 1015 & 1552 & 0.76 & 0.24 \\
\hline M & Drug psychoses (292) & 42 & 2531 & 2716 & 1302 & 1124 & 0.71 & 0.29 \\
\hline M & Transient org mental disorder (293) & 64 & 2236 & 11165 & 1024 & 2394 & 0.82 & 0.18 \\
\hline M & Other organic psych condition (294) & 65 & 1954 & 7979 & 1560 & 2900 & 0.73 & 0.27 \\
\hline M & Schizophrenic disorders (295) & 44 & 1982 & 97263 & 1614 & 63650 & 0.6 & 0.4 \\
\hline M & Affective psychoses (296) & 52 & 2228 & 72092 & 1589 & 36485 & 0.66 & 0.34 \\
\hline M & Paranoid states (297) & 58 & 2269 & 4235 & 1412 & 1254 & 0.77 & 0.23 \\
\hline M & Other nonorganic psychoses (298) & 49 & 2465 & 21743 & 917 & 5739 & 0.79 & 0.21 \\
\hline M & Psychoses of childhood (299) & 30 & 2355 & 1165 & 1122 & 81 & 0.93 & 0.07 \\
\hline \multicolumn{9}{|c|}{ Neurotic disorders, personality disorders, and other nonpsychotic mental disorders (300-316) } \\
\hline M & Neurotic disorders (300) & 54 & 1893 & 162548 & 1521 & 98138 & 0.62 & 0.38 \\
\hline M & Personality disorders (301) & 44 & 1784 & 8795 & 1880 & 6694 & 0.57 & 0.43 \\
\hline M & Sexual disorders (302) & 55 & 1980 & 13929 & 1478 & 8231 & 0.63 & 0.37 \\
\hline M & Alcohol dependence syndrome(303) & 50 & 1916 & 21938 & 1368 & 13052 & 0.63 & 0.37 \\
\hline M & Drug dependence (304) & 42 & 2089 & 20021 & 1250 & 8198 & 0.71 & 0.29 \\
\hline M & Nondependent drug abuse (305) & 47 & 1916 & 8784 & 1465 & 5747 & 0.6 & 0.4 \\
\hline M & Psycho-physiological gastro-intestinal disorder (306) & 56 & 1144 & 2630 & 1562 & 3633 & 0.42 & 0.58 \\
\hline M & Special symptom (307) & 53 & 2002 & 15892 & 1281 & 8388 & 0.65 & 0.35 \\
\hline M & Acute reaction to stress (308) & 55 & 1837 & 22896 & 1517 & 14600 & 0.61 & 0.39 \\
\hline M & Adjustment reaction (309) & 49 & 1937 & 47373 & 1465 & 25840 & 0.65 & 0.35 \\
\hline M & Nonpsychotic brain syndrome(310) & 51 & 1607 & 7694 & 1246 & 3007 & 0.72 & 0.28 \\
\hline M & Depressive disorder (311) & 54 & 2045 & 198459 & 1468 & 103753 & 0.66 & 0.34 \\
\hline M & Conduct disturbance (312) & 52 & 2174 & 4065 & 1570 & 1821 & 0.69 & 0.31 \\
\hline M & Emotional disorder childhood/adolescence (313) & 41 & 1613 & 1234 & 1386 & 1203 & 0.51 & 0.49 \\
\hline M & Hyperkinetic syndrome (314) & 39 & 2080 & 4839 & 1463 & 1915 & 0.72 & 0.28 \\
\hline M & Specific developmental delays (315) & 33 & 2407 & 807 & 1286 & 528 & 0.6 & 0.4 \\
\hline M & Psychic factor associated with other disorder (316) & 57 & 2006 & 4011 & 1290 & 2363 & 0.63 & 0.37 \\
\hline \multicolumn{9}{|c|}{ Mental retardation (317-319) } \\
\hline M & Mild intellectual disability (317) & 40 & 2052 & 1032 & 1724 & 855 & 0.55 & 0.45 \\
\hline M & Other mental retardation (318) & 37 & 2085 & 583 & 2460 & 798 & 0.42 & 0.58 \\
\hline M & Intellectual disability NOS (319) & 42 & 2099 & 416 & 1650 & 217 & 0.66 & 0.34 \\
\hline Gender & Any $\mathrm{MD}$ is pivot & Age, years & $\begin{array}{l}\text { MD before } \\
\text { CA, days }\end{array}$ & $\begin{array}{l}\text { MD before } \mathrm{CA} \\
\text { Frequency }\end{array}$ & $\begin{array}{l}\text { MD after } \mathrm{CA} \text {, } \\
\text { days }\end{array}$ & $\begin{array}{l}\text { MD after CA } \\
\text { Frequency }\end{array}$ & $\begin{array}{l}\text { Proportion } \\
\text { MD before }\end{array}$ & $\begin{array}{l}\text { Proportion } \\
\text { MD after }\end{array}$ \\
\hline \multicolumn{9}{|c|}{ Malignant neoplasm of lip, oral cavity, and pharynx (140-149) } \\
\hline M & Mal neo lip (140) & 69 & 2064 & 2377 & 991 & 285 & 0.89 & 0.11 \\
\hline M & Mal neo tongue (141) & 58 & 2154 & 1377 & 344 & 203 & 0.87 & 0.13 \\
\hline M & Mal neo major salivary (142) & 58 & 2342 & 343 & 891 & 90 & 0.79 & 0.21 \\
\hline M & Mal neo gum (143) & 62 & 2019 & 112 & 801 & 11 & 0.91 & $\begin{array}{c}0.09 \\
\text { (Continued) }\end{array}$ \\
\hline
\end{tabular}




\begin{tabular}{|c|c|c|c|c|c|c|c|c|}
\hline Gender & Any MD is pivot & Age, years & $\begin{array}{r}\text { MD before } \\
\text { CA, days }\end{array}$ & $\begin{array}{l}\text { MD before CA } \\
\text { Frequency }\end{array}$ & $\begin{array}{l}\text { MD after CA, } \\
\text { days }\end{array}$ & $\begin{array}{l}\text { MD after CA } \\
\text { Frequency }\end{array}$ & $\begin{array}{l}\text { Proportion } \\
\text { MD before }\end{array}$ & $\begin{array}{r}\text { Proportion } \\
\text { MD after }\end{array}$ \\
\hline M & Mal neo mouth floor (144) & 61 & 1855 & 281 & 524 & 31 & 0.9 & 0.1 \\
\hline M & Mal neo of other and unspecified parts of mouth (145) & 61 & 2000 & 1015 & 508 & 158 & 0.87 & 0.13 \\
\hline M & Mal neo oropharynx (146) & 61 & 2300 & 776 & 528 & 103 & 0.88 & 0.12 \\
\hline M & Mal neo nasopharynx (147) & 59 & 2053 & 932 & 571 & 190 & 0.83 & 0.17 \\
\hline M & Mal neo hypopharynx (148) & 59 & 1614 & 373 & 449 & 45 & 0.89 & 0.11 \\
\hline M & Other mal neo oropharynx (149) & 61 & 1493 & 159 & 423 & 39 & 0.8 & 0.2 \\
\hline \multicolumn{9}{|c|}{ Malignant neoplasm of digestive organs and peritoneum (150-159) } \\
\hline M & Mal neo oesophagus (150) & 66 & 2498 & 5111 & 416 & 539 & 0.9 & 0.1 \\
\hline M & Mal neo stomach (151) & 67 & 1957 & 3194 & 421 & 398 & 0.89 & 0.11 \\
\hline M & Mal neo small bowel (152) & 65 & 2376 & 504 & 714 & 51 & 0.91 & 0.09 \\
\hline M & Mal neo colon (153) & 68 & 2090 & 14091 & 695 & 2387 & 0.86 & 0.14 \\
\hline M & Mal neo rectum/anus (154) & 67 & 2110 & 6976 & 726 & 1900 & 0.79 & 0.21 \\
\hline M & Mal neo liver (155) & 62 & 2144 & 4929 & 515 & 414 & 0.92 & 0.08 \\
\hline M & Mal neo/extrahepatic bile ducts (156) & 65 & 1994 & 955 & 232 & 96 & 0.91 & 0.09 \\
\hline M & Mal neo pancreas (157) & 69 & 2168 & 6034 & 367 & 520 & 0.92 & 0.08 \\
\hline M & Mal neo peritoneum (158) & 65 & 2340 & 364 & 523 & 16 & 0.96 & 0.04 \\
\hline M & Other mal neo gastro-intestine/peritoneum (159) & 67 & 1863 & 322 & 606 & 42 & 0.88 & 0.12 \\
\hline \multicolumn{9}{|c|}{ Malignant neoplasm of respiratory and intrathoracic organs (160-165) } \\
\hline M & Mal neo nasal cavity/sinus (160) & 55 & 2211 & 505 & 1054 & 90 & 0.85 & 0.15 \\
\hline M & Mal neo larynx (161) & 66 & 2268 & 2378 & 794 & 488 & 0.83 & 0.17 \\
\hline M & Mal neo trachea/lung (162) & 69 & 2159 & 24863 & 428 & 3116 & 0.89 & 0.11 \\
\hline M & Mal neo pleura (163) & 66 & 2046 & 720 & 456 & 84 & 0.9 & 0.1 \\
\hline M & Mal neo of thymus, heart, and mediastinum (164) & 60 & 2414 & 553 & 349 & 105 & 0.84 & 0.16 \\
\hline M & $\begin{array}{l}\text { Mal neo of other and ill-defined sites within the respiratory system } \\
\text { and intrathoracic organs (165) }\end{array}$ & 53 & 2242 & 605 & 996 & 130 & 0.82 & 0.18 \\
\hline \multicolumn{9}{|c|}{ Malignant neoplasm of bone, connective tissue, skin, and breast (170-175) } \\
\hline M & Mal neo bone/artic cart (170) & 54 & 1792 & 1206 & 532 & 181 & 0.87 & 0.13 \\
\hline M & Mal neo soft tissue (171) & 55 & 2106 & 2376 & 592 & 528 & 0.82 & 0.18 \\
\hline M & Mal melanoma skin (172) & 62 & 2245 & 5453 & 1090 & 1124 & 0.83 & 0.17 \\
\hline M & Other mal neo skin (173) & 70 & 2407 & 46374 & 1215 & 13512 & 0.77 & 0.23 \\
\hline M & Mal neo male breast (175) & 63 & 2049 & 146 & 1337 & 26 & 0.85 & 0.15 \\
\hline \multicolumn{9}{|c|}{ Malignant neoplasm of genitourinary organs (179-189) } \\
\hline M & Mal neo prostate (185) & 72 & 2074 & 41723 & 1041 & 7643 & 0.85 & 0.15 \\
\hline M & Mal neo testis (186) & 44 & 1769 & 1374 & 1072 & 425 & 0.76 & 0.24 \\
\hline M & Mal neo male genital (187) & 63 & 2077 & 609 & 1070 & 108 & 0.85 & 0.15 \\
\hline M & Mal neo bladder (188) & 72 & 2283 & 16695 & 1059 & 3609 & 0.82 & 0.18 \\
\hline M & Mal neo of kidney and other and unspecified urinary organs (189) & 66 & 2362 & 5503 & 833 & 772 & 0.88 & 0.12 \\
\hline \multicolumn{9}{|c|}{ Malignant neoplasm of other and unspecified sites (190-199) } \\
\hline M & Mal neo eye (190) & 59 & 2145 & 600 & 902 & 111 & 0.84 & 0.16 \\
\hline M & Mal neo brain (191) & 55 & 1908 & 5222 & 433 & 630 & 0.89 & 0.11 \\
\hline M & Mal neo of other and unspecified parts of nervous system (192) & 59 & 2521 & 328 & 1175 & 35 & 0.9 & 0.1 \\
\hline M & Mal neo thyroid (193) & 59 & 1672 & 1359 & 857 & 223 & 0.86 & 0.14 \\
\hline M & Mal neo other endocrine (194) & 59 & 2658 & 496 & 1137 & 67 & 0.88 & 0.12 \\
\hline M & Mal neo other/ill-defined site (195) & 66 & 1977 & 682 & 521 & 83 & 0.89 & 0.11 \\
\hline M & Mal neo lymph nodes (196) & 62 & 2303 & 1134 & 1061 & 199 & 0.85 & 0.15 \\
\hline M & Secondary (sec) mal neo of respiratory and digestive systems (197) & 66 & 1798 & 1675 & 381 & 189 & 0.9 & 0.1 \\
\hline M & Sec mal neo other sites (198) & 63 & 2146 & 760 & 428 & 61 & 0.93 & 0.07 \\
\hline
\end{tabular}


signalling in the central nervous system, but also affect communication across all cellular systems, such as immune system regulation. ${ }^{40}$

Age represented a potential confounder of the results; hence, age was stratified into two groups, with the finding that the overall and temporal relationships of cancer and mental disorder were independent of age. This strengthens the idea that there may be a mechanism operating separately from the process of simple functional decline. ${ }^{41-46}$

In summary, this paper provides a description of the overall relationship between cancer and mental disorder in a large North American population. More directly related to clinical utility are descriptions of the frequencies and the average times in days with which specific diagnoses arise either following or in advance of cancer and mental disorder. For example, frequencies of specific cancers or mental disorders arising before or after the pivot class may represent an index of that specific disorder's intensity in patients, and may indicate the need for further screening or investigation.

\section{Limitations, conclusion and next steps}

We recognise that only cancer and mental disorder were considered in this paper. The relationships within and between the remaining classes of ICD disorders are also important and warrant more detailed study. Although the present work remains illuminating, and we contend that it is congruent with developments in laboratory and biological research, a complete list of disorders leading to and from a given pivot diagnosis is a worthy pursuit. Notwithstanding the complexity of conducting a metabolomics study at a population level, the main limitation of this contribution is the need to await the development of the algorithms required to develop the temporal roadmaps within and between the thousands of diagnoses underpinning the 18 main ICD classes of disorder. In such algorithms, the native patterns of the relationships arising in sequence among related disorders within patients would be preserved. Comparison of the average durations by specific diagnosis only provides a crude index of sequence; however, these calculations are independent for each specific diagnosis arising either before or after the pivot class diagnosis.

Another main limitation is that the present paper cannot resolve a clear understanding of the mechanism underpinning the temporal relationship between mental disorder and cancer. The results mainly introduce the additional confounder of psychiatric treatment. The relationship between brain function, the effects of antipsychotics and immune function is appealing in its simplicity in terms of basic research models testable in laboratory settings. Regardless, a great deal of work remains to design and implement studies that might resolve mechanistic issues such as treatment with antipsychotics and common constitutional and epigenetic vulnerability, as well as the influence of environmental and sociocultural factors.

David Cawthorpe, PhD, Professor (Adjunct), Faculty of Medicine, Departments of Psychiatry \& Community Health Sciences, Institute for Child and Maternal Health, University of Calgary, Alberta, Canada; Marc Kerba, BSC, MD, MPA, FRCPC, Department of Oncology, University of Calgary, Alberta, Canada; Aru Narendran, MD, PhD, Pediatric Oncology Experimental Therapeutics Investigators Consortium (POETIC) Laboratory, Department of Oncology, Cumming School of Medicine, University of Calgary, Alberta, Canada; Harleen Ghuttora, MSc, Master of Biomedical Technology, University of Calgary, and Program Coordinator - Health, Genome Alberta, Canada; Gabrielle Chartier, MD MSc, Department of Psychiatry, University of British Columbia, Vancouver, Canada; Norman Sartorius, MD, PhD, FRCPsych, Visiting Professor at the Institute of Psychiatry, London, UK, Adjunct Professor at the University of St Louis, New York, USA, and President Association for the Improvement of Mental Health Programmes, Geneva, Switzerland.

Correspondence: David Cawthorpe, Richmond Road Diagnostic and Treatment Center 2nd Floor, RM 2603, 1820 Richmond Road S.W. Calgary, Alberta T2T 5C7, Canada. Email: cawthord@ucalgary.ca

First received 4 Jan 2018, accepted 12 Jan 2018

\section{References}

1 Jakovljevic M, Ostojic L. Comorbidity and multimorbidity in medicine today: challenges and opportunities for bringing separated branches of medicine closer to each other. Psychiatr Danub 2013; 25(suppl 1): 18-28.

2 Feinstein AR. The pre-therapeutic classification of co-morbidity in chronic disease. J Chronic Dis 1970; 23: 455-68.

3 Ahern TP, Horvath-Puho E, Spindler KL, Sorensen HT, Ording AG, Erichsen R. Colorectal cancer, comorbidity, and risk of venous thromboembolism: assessment of biological interactions in a Danish nationwide cohort. Br J Cancer 2016; 114: 96-102.

4 Alexander M, Evans SM, Stirling RG, Wolfe R, Officer A, MacManus M, et al. The influence of comorbidity and the simplified comorbidity score on overall survival in non-small cell lung cancer - a prospective cohort study. J Thorac Oncol 2016; 11: 748-57.

5 Asano T, Yamada S, Fujii T, et al. The Charlson age comorbidity index predicts prognosis in patients with resected pancreatic cancer. Int J Surg 2017; 39: 169-175.

6 Baumeister P, Rauch J, Jacobi C, et al. Impact of comorbidity and anemia in patients with oropharyngeal cancer primarily treated with surgery in the human papillomavirus era. Head Neck 2017; 39: 7-16.

7 Boehm K, Dell'Oglio P, Tian Z, et al. Comorbidity and age cannot explain variation in life expectancy associated with treatment of non-metastatic prostate cancer. World J Urol 2016; 35: 1031-6.

8 Corraini P, Ording AG, Henderson VW, Szepligeti S, Horvath-Puho E, Sorensen HT. Cancer, other comorbidity, and risk of venous thromboembolism after stroke: a population-based cohort study. Thromb Res 2016; 147: 88-93.

9 Elshaikh MA, Vance S, Kamalignant M, et al. Influence of comorbidity on the risk of death: a single institution study of 1132 women with early-stage uterine cancer. Am J Clin Oncol 2017; 40: 183-8.

10 Gollnitz I, Inhestern J, Wendt TG, et al. Role of comorbidity on outcome of head and neck cancer: a population-based study in Thuringia, Germany. Cancer Med 2016; 5: 3260-71.

11 Halvorsen TO, Sundstrom S, Flotten O, et al. Comorbidity and outcomes of concurrent chemo- and radiotherapy in limited disease small cell lung cancer. Acta Oncol 2016; 55: 1349-54.

12 Hiyoshi A, Fall K, Bergh C, Montgomery S. Comorbidity trajectories in working age cancer survivors: a national study of Swedish men. Cancer Epidemiol 2017; 48: 48-55.

13 Ichikawa H, Kosugi SI, Kanda T, et al. Surgical and long-term outcomes following oesophagectomy in oesophageal cancer patients with comorbidity. Int J Surg 2016; 36: 212-8.

14 Kaul S, Veeranki SP, Rodriguez AM, Kuo YF. Cigarette smoking, comorbidity, and general health among survivors of adolescent and young adult cancer. Cancer 2016; 122: 2895-905

15 Chang CM, Yin WY, Wei CK, et al. Correction: adjusted age-adjusted Charlson comorbidity index score as a risk measure of perioperative mortality before cancer surgery. PLOS One 2016; 11: e0157900.

16 Froehner M, Koch R, Hubler M, Wirth MP. Validation of an age-adjusted prostate cancer-specific comorbidity index. Eur Urol 2016; 69: 764-6.

17 Giugliano FM, Falivene S, Esposito E, et al. Short-course radiotherapy in elderly women with breast cancer: comparison by age, comorbidity index and toxicity. Int J Surg 2016; 33(suppl 1): S92-6.

18 Guldberg TL, Christensen S, Zachariae R, Jensen AB. Prognostic factors in early breast cancer associated with body mass index, physical functioning, physical activity, and comorbidity: data from a nationwide Danish cohort. Breast Cancer Res Treat 2017; 162: 159-67.

19 Keshtgarpour M, Tan WS, Zwanziger J, Awadalla S, Langi FG, Dudek AZ. Prognostic value of serum proteomic test and comorbidity index in diversified population with lung cancer. Anticancer Res 2016; 36: 1759-65.

20 Lee JY, Kang HW, Rha KH et al. Age-adjusted Charlson comorbidity index is a significant prognostic factor for long-term survival of patients with high-risk prostate cancer after radical prostatectomy: a Bayesian model averaging approach. J Cancer Res Clin Oncol 2016; 142: 849-58.

21 Noer MC, Sperling CD, Antonsen SL, Ottesen B, Christensen IJ, Hogdall C. A new clinically applicable age-specific comorbidity index for preoperative risk assessment of ovarian cancer patients. Gynecol Oncol 2016; 141: 471-8.

22 Otake S, Ohtsuka T, Asakura K, Kamiyama I, Kohno M. Impact of comorbidity index on morbidity and survival in non-small cell lung cancer. Asian Cardiovasc Thorac Ann 2016; 24: 30-3.

23 singh N, Singh PS, Aggarwal AN, Behera D. Comorbidity assessment using Charlson comorbidity index and simplified comorbidity score and its association with clinical outcomes during first-line chemotherapy for lung cancer. Clin Lung Cancer 2016; 17: 205-13. 
24 Tanaka H, Takenaka Y, Nakahara S, et al. Age-adjusted Charlson comorbidity index as a prognostic factor of hypopharyngeal cancer treated with chemoradiation therapy. Acta Otolaryngol 2017; 137: 668-73.

25 Tian Y, Xu B, Yu G, Li Y, Liu H. Age-adjusted Charlson comorbidity index score as predictor of prolonged postoperative ileus in patients with colorectal cancer who underwent surgical resection. Oncotarget 2017; 8: 20794-801.

26 Keszte J, Danker H, Dietz A, et al. Course of psychiatric comorbidity and utilization of mental health care after laryngeal cancer: a prospective cohort study. Eur Arch Otorhinolaryngol 2017; 274: 1591-9.

27 Ng HS, Roder D, Koczwara B, Vitry A. Comorbidity, physical and mental health among cancer patients and survivors: an Australian population-based study. Asia Pac J Clin Oncol 2017; DOI: 10.1111/ajco.12677.

28 Faller $\mathrm{H}$, Weis $\mathrm{J}$, Koch $\mathrm{U}$, et al. Perceived need for psychosocial support depending on emotional distress and mental comorbidity in men and women with cancer. J Psychosom Res 2016; 81: 24-30.

29 Nakash O, Levav I, Guilar-Gaxiola S, et al. Comorbidity of common mental disorders with cancer and their treatment gap: findings from the World Menta Health Surveys. Psychooncology 2014; 23: 40-51.

30 Lu D, Andersson TM, Fall K, et al. Clinical diagnosis of mental disorders immediately before and after cancer diagnosis: a nationwide matched cohort study in Sweden. JAMA Oncol 2016; 2: 1188-96.

31 Cawthorpe D, Davidson M. Temporal comorbidity of mental disorder and ulcerative colitis. Perm J 2015; 19: 52-7.

32 Mantovani A, Allavena P, Sica A, Balkwill F. Cancer-related inflammation. Nature 2008; 454: 436-44

33 Coussens LM, Werb Z. Inflammation and cancer. Nature 2002; 420: 860-7.

34 Mantovani A, Marchesi F, Porta C, Sica A, Allavena P. Inflammation and cancer: breast cancer as a prototype. Breast 2007; 16(suppl 2): S27-33.

35 Chiang AC, Massague J. Molecular basis of metastasis. N Engl J Med 2008; 359 2814-23.

36 Paul B, Barnes S, Mark-Wahnefried W, et al. Influences of diet and the gut microbiome on epigenetic modulation in cancer and other diseases. Clin Epigenetics 2015; 7: 112
37 Alam R, Abdolmaleky HM, Zhou JR. Microbiome, inflammation, epigenetic alterations, and mental diseases. Am J Med Genet B Neuropsychiatr Genet 2017; 174: 651-60.

38 Batlle E, Wilkinson DG. Molecular mechanisms of cell segregation and boundary formation in development and tumorigenesis. Cold Spring Harb Perspect Biol 2012; 4: a008227.

39 Zhu J, Fang F, Sjolander A, Fall K, Adami HO, Valdimarsdottir U. First-onset mental disorders after cancer diagnosis and cancer-specific mortality: a nationwide cohort study. Ann Oncol 2017; 28: 1964-9.

40 Trakhtenberg EF, Goldberg JL. The role of serotonin in axon and dendrite growth. Int Rev Neurobiol 2012; 106: 105-26.

41 Kenis C, Decoster L, Bastin J, et al. Functional decline in older patients with cancer receiving chemotherapy: a multicenter prospective study. J Geriatr Oncol 2017; 8: 196-205

42 Owusu C, Margevicius S, Schluchter M, Koroukian SM, Schmitz KH, Berger NA Vulnerable elders survey and socioeconomic status predict functional decline and death among older women with newly diagnosed nonmetastatic breast cancer. Cancer 2016; 122: 2579-86.

43 Granger $\mathrm{CL}$, McDonald CF, Irving L, et al. Low physical activity levels and functional decline in individuals with lung cancer. Lung Cancer 2014; 83: 292-9.

44 Hoppe $\mathrm{S}$, Rainfray $\mathrm{M}$, Fonck $\mathrm{M}$, et al. Functional decline in older patients with cancer receiving first-line chemotherapy. J Clin Oncol 2013; 31: 3877-82.

45 Atlas A, Grimmer K, Kennedy K. Early indications that low mental quality of life scores in recently unwell older people predict downstream functional decline. Clin Interv Aging 2015; 10: 703-12.

46 Lee $\mathrm{Y}$. The predictive value of self assessed general, physical, and mental health on functional decline and mortality in older adults. J Epidemiol Community Health 2000; 54: 123-9. 